\title{
OUTROS TEMAS \\ Discursos na Institucionalização do Ensino de Espanhol em Niterói/RJ
}

\author{
Diego da Silva Vargas' \\ Alice Moraes Rego de Souza" \\ 'Universidade Federal do Estado do Rio de Janeiro (UNIRIO), \\ Rio de Janeiro/RJ - Brasil \\ "Centro Federal de Educação Tecnológica Celso Suckow da Fonseca (CEFET), \\ Rio de Janeiro/RJ-Brasil
}

RESUMO - Discursos na Institucionalização do Ensino de Espanhol em Niterói/RJ. O artigo problematiza o currículo como espaço de poder e de produção de subjetividades comprometido com diferentes projetos de formação básica, partindo do processo de institucionalização do ensino de Espanhol na rede municipal de Niterói/RJ - situado no cerne de conflitos discursivos. Para tal, articula-se a visão discursiva de linguagem à perspectiva cartográfica, com vistas a mapear o processo de significação do ensino de uma língua estrangeira em meio a políticas linguísticas e cognitivas. As análises dedicam-se ao referencial curricular, ao livro didático e à avaliação e evidenciam um embate entre visões de (ensino de) língua, das estruturais às utilitaristas, voltadas à formação para o mercado.

Palavras-chave: Currículo. Avaliação. Ensino de Espanhol. Políticas Cognitivas.

\begin{abstract}
Discourses in the Institutionalization of Spanish Teaching in Niterói/RJ. The paper problematizes the curriculum as a space of power and production of subjectivities committed to different basic education projects, starting from the process of institutionalizing the teaching of Spanish in municipal schools of Niterói/RJ - understanding it as a result of discursive conflicts. To this end, the discursive view of language is articulated with the cartographic perspective, in order to map the process of signifying the teaching of a foreign language amidst linguistic and cognitive policies. The analyzes are dedicated to the curricular framework, the textbook and the evaluation and show a clash between visions of (teaching of) language, from structural to utilitarian, aimed at training for the market.
\end{abstract}

Keywords: Curriculum. Evaluation. Spanish Teaching. Cognitive Policies.

Educação \& Realidade, Porto Alegre, v. 46, n. 2, e108008, 2021. 
Discursos na Institucionalização do Ensino de Espanhol em Niterói/RJ

\section{Introdução}

Vivemos um contexto de ataques à educação pública e de disputas para determinar o que (não) deve habitar currículos e práticas escolares. Discursos neocoloniais têm se aproximado do debate educacional, fortalecendo ações excludentes e voltadas aos interesses do mercado ${ }^{1}$. Nesse cenário, este artigo busca analisar o processo de implementação do ensino de Espanhol como disciplina dos anos finais do Ensino Fundamental (EF) na rede municipal de Niterói, tomado como a concretização de políticas linguísticas e cognitivas decorrentes de conflitos discursivos acerca de concepções de (ensino de) línguas estrangeiras ${ }^{2}$ (LE) como parte de um projeto de Educação Básica.

Tal proposta ganha relevância diante do enfraquecimento do plurilinguismo nas políticas de currículo brasileiras, por um lado, reforçando o discurso neoliberal que associa o estudo do Inglês à formação de mão de obra para o mercado de trabalho (Souza, 2019) e, por outro lado, fragilizando o ensino do Espanhol na Educação Básica, mesmo que essa língua se faça cada vez mais presente no cotidiano brasileiro. Parte desse retrocesso se deu com a obrigatoriedade do ensino de Inglês no Ensino Médio (EM) e nos anos finais do EF, imposta pela Lei ${ }^{\circ}$ 13.415/2017, cujos desdobramentos se veem: a) na publicação de uma Base Nacional Comum Curricular (BNCC) que suprimiu o componente Língua Estrangeira Moderna, substituindo-o pela Língua Inglesa; b) na exclusão do Espanhol do Programa Nacional do Livro Didático (PNLD).

Em relação à rede municipal de Niterói, a implementação do ensino de Espanhol nos anos finais do EF se deu em 2011, em um momento de expansão da disciplina no Brasil. Dessa maneira, retomamos esse contexto que nos é mais próximo com o objetivo de mapear e entender conflitos que se materializam a partir do modo como o ensino de LE tem se constituído e dos projetos de formação básica aos quais tem se aliado. Aqui, entendemos a LE como uma disciplina que integra um projeto maior de formação e, portanto, as concepções de língua que sustentam nos mostram também sua vinculação a práticas mais ou menos comprometidas com a educação linguística ${ }^{3}$.

Construímos, então, um movimento cartográfico com viés interventivo (Barros; Kastrup, 2012) em que o olhar do pesquisador é central na construção de seu objeto de pesquisa (tomado como processualidade), de modo que nossas memórias e vivências nos motivaram a analisar enunciados atrelados à implementação do Espanhol na rede municipal de Niterói. A intervenção se coloca no fluxo das análises, direcionada a reflexões sobre a dimensão do comum $^{4}$ envolvida na construção curricular de uma disciplina escolar, tomada como território de disputas (Arroyo, 2011).

Recortamos como corpus analítico um espaço discursivo (Maingueneau, 2008) formado pelos seguintes enunciados: os Referenciais Curriculares de Língua Espanhola da rede municipal de Niterói; o livro didático adotado nos primeiros anos de sua implementação nessa rede; e a prova de Língua Espanhola aplicada, em 2013, pelo Sistema de 
Avaliação da Educação de Niterói (SAEN) - primeira avaliação de larga escala da rede. Cabe destacar que atuamos como professores da rede entre o ano de 2011 e os anos de 2014 e 2015. Assim, integramos este processo de institucionalização, tendo participado dele na construção da segunda versão dos Referenciais Curriculares e principalmente por meio de nossa atuação em sala de aula.

Iniciamos este texto com o mapeamento da trajetória do ensino de espanhol no Brasil e sua relação com diferentes políticas educacionais, linguísticas e cognitivas, para, em seguida, estabelecer diálogos entre os estudos em currículo e em avaliação como base para a construção das análises, articulando a perspectiva discursiva de linguagem (Maingueneau, 2008; 2015) e o conceito de políticas cognitivas (Kastrup, 2005; 2012).

\section{Cartografando Políticas Linguísticas, Cognitivas e Educacionais no Ensino de Espanhol}

Toda disciplina escolar passa por um processo de institucionalização que estrutura sua constituição sócio-histórica e, nesse processo, define seus objetivos de organização e agrega formas de conhecimento, práticas culturais, padrões cognitivos, interacionais e discursivos, sistemas de crenças e estruturas de expectativa específicas (Gerhardt, 2013). Assim, antes de entrarmos no processo de implementação do Espanhol na rede de Niterói, buscamos cartografar a trajetória da disciplina no Brasil, visto que os discursos que constituem tal trajetória e fazem circular sentidos sobre (ensino de) língua também participam dos processos construídos contemporaneamente.

Concordando com Rajagopalan (2003) quando aponta o componente político presente no debate sobre o ensino de línguas, concebemos que a trajetória de constituição curricular de uma língua em uma disciplina escolar é resultado do cruzamento de políticas educacionais, linguísticas e cognitivas. Tais políticas, em nossa perspectiva, se constroem no âmbito de conflitos interdiscursivos (Maingueneau, 2008) resultado de negociações entre diferentes posicionamentos -, por meio de enunciados que registram processos oficiais, mas também em práticas discursivas cotidianas, (re)construindo-se nas ações docentes e discentes.

Desse modo, o mapeamento registrado nesta seção dá visibilidade ao campo discursivo das políticas de ensino de LE, entendendo-o como

[...] um conjunto de formações discursivas que se encontram em concorrência, delimitam-se reciprocamente em uma região determinada do universo discursivo. 'Concorrência' deve ser entendida da maneira mais ampla; ela inclui tanto o confronto aberto quanto a aliança, a neutralidade aparente etc... entre discursos que possuem a mesma função social e divergem sobre o modo pelo qual ela deve ser preenchida (Maingueneau, 2008, p. 34). 
Discursos na Institucionalização do Ensino de Espanhol em Niterói/RJ

Estamos tratando, então, de concorrências entre posicionamentos discursivos que constituem o campo político-educacional, ou seja, que implicam relações de ensino-aprendizagem e envolvem embates entre políticas de cognição. Tal conceito parte da noção de que uma concepção de aprendizagem sempre emerge dos discursos sobre e das práticas de ensino. Segundo Kastrup (2012, p. 56), a política cognitiva é "[...] um modo específico de relação com o conhecimento, com o mundo e consigo mesmo". Assim, partindo do princípio da não separação entre (construção do) conhecimento, (produção de) subjetividades e política, Kastrup $(2005 ; 2012)$ entende que a ideia que temos do que é o conhecimento e do que é a aprendizagem vai além de posicionamentos teóricos e constituem políticas da cognição.

Tais políticas podem ser de dois tipos: a) de recognição (ou de representação), segundo a qual, sujeitos e mundos são preexistentes às situações de aprendizagem, que se dão sempre baseadas na resolução de problemas de acordo com regras lógicas; b) de invenção, segundo a qual, mundos e subjetividades são efeitos de práticas. Nessa concepção, a aprendizagem se daria não a partir da resolução, mas sim, da invenção de problemas, tomada como práticas de conhecer (Kastrup, 2005; 2012). As políticas cognitivas, portanto, se manifestam em nossa prática cotidiana, mas também em políticas públicas, em nosso caso, educacionais e linguísticas e participam das relações de concorrência (Maingueneau, 2008) também no âmbito discursivo.

A seguir, portanto, buscamos remontar, em parte, tal campo discursivo e discutir sobre as perspectivas que entram em embate, por meio da implementação de distintas políticas voltadas ao ensino de LE no Brasil. Em nosso país, o ensino de LE data do processo de colonização (Daher, 2006), entretanto, no que se refere à construção da Língua Espanhola como disciplina escolar, partimos do que Celada e González (2000) apontam como gesto fundador, isto é, o percurso de institucionalização dessa disciplina na escola brasileira, iniciado com a entrada de Antenor Nascentes, em 1919, no Colégio Pedro II.

Em 1934, Nascentes publica a primeira gramática da língua espanhola voltada a aprendizes brasileiros, tendo por base o princípio contrastivo (Daher, 2006). Essa gramática se torna o principal referencial para o ensino de Espanhol no país, sendo a base para o primeiro manual para o ensino dessa língua no Brasil - o Manual de Idel Becker, publicado em 1945. Assim se institui uma perspectiva sobre o ensino de Espanhol no Brasil: baseada no contraste e na busca de diferenças entre as línguas portuguesa e espanhola (Celada; González, 2000). Sobre isso, Vargas (2017, p. 141) aponta que

[...] se inaugura assim uma política cognitiva acerca de como e por que a língua espanhola precisa ser ensinada aos brasileiros - uma política cognitiva que traz consigo a marca da recognição, uma vez que, por mais que se ressalte a necessidade de uso de gêneros do cotidiano, as línguas são entendidas como prévias e acabadas em si mesmas e que, portanto, cabe ao aprendiz, que está alheio a 
elas, compará-las para que não tenha um conhecimento superficial e assim resolva suas dificuldades, que também são pré-determinadas, uma vez que elas se encontram na língua e não nos aprendizes.

Somente em 1942, com a chamada Reforma Capanema e a criação da Lei Orgânica do Ensino Secundário, o Espanhol se torna disciplina obrigatória, substituindo, não ao acaso, o alemão, e sendo ofertada no $1^{\circ}$ ano dos cursos Clássico ou Científico e com carga menor do que as outras línguas: francês, inglês, latim e grego (Daher, 2006; Freitas; Barreto, 2007). Daher (2006) afirma que tal reforma também sugeria a adoção do método direto no ensino, ou seja, com a ênfase na língua oral, através de diálogos e pequenas leituras e, só posteriormente, exercícios escritos. Esse seria o primeiro método a buscar a integração das chamadas quatro habilidades (ouvir, falar, ler e escrever, nessa ordem), mas não foi adotado plenamente pelos professores, que ainda preferiam a abordagem da gramática e da tradução (Leffa, 1988).

Ainda que a mudança de método não necessariamente transforme as políticas cognitivas envolvidas no processo de ensino-aprendizagem de uma língua, aqui é interessante observar como perspectivas teórico-metodológicas, mesmo impostas em lei, não adentram o espaço de maneira amistosa, o que reforça a já apontada noção de concorrência (como disputa e como aliança).

Sem qualquer menção ao ensino de LE na primeira LDB - Lei de Diretrizes e Bases da Educação de 1961 -, a língua espanhola foi perdendo espaço nos currículos escolares e praticamente desapareceu, já que sua presença não estava consolidada (Daher, 2006; Rodrigues, 2010). Em 1971, a nova LDB sugere que as LE podem ser escolhidas pelos Conselhos Estaduais de Educação (CEE), e em 1976, com a Resolução 58/76 do Conselho Nacional de Educação, a obrigatoriedade das línguas no núcleo comum do $2^{\circ}$ grau retorna, com a recomendação de sua inclusão no $1^{\circ}$ grau. A escolha das línguas ainda era função dos CEE, o que mantinha o espanhol na mesma condição (Rodrigues, 2010; Freitas, 2011).

Um movimento para alterar essa situação se inicia nos anos 1980, com a fundação das Associações de Professores de Espanhol e a reivindicação da inserção do Espanhol nas redes municipais e estaduais de ensino do país. No Rio de Janeiro, um movimento da Associação deste estado conseguiu aprovar leis que tornaram obrigatório o Espanhol em escolas de $1^{\circ} \mathrm{e}$ de $2^{\circ}$ graus do estado e do município (Daher, 2006; Freitas; Barreto, 2007). Apesar da ampliação de sua oferta nas redes públicas, hoje essas leis, ainda vigentes, são descumpridas.

Com a LDB de 1996, alterou-se a situação das LE nos currículos escolares, ao definir que uma língua estrangeira moderna escolhida pela comunidade escolar, obrigatoriamente, deveria ser ensinada no segundo segmento do EF. No EM, deveria ser disponibilizada outra, em caráter optativo, dentro das possibilidades da instituição (Freitas; Barreto, 2007; Rodrigues, 2010). A situação do Espanhol não foi alterada, já que a LDB não mencionava quais línguas deveriam ser ensinadas, mas, com a 
Discursos na Institucionalização do Ensino de Espanhol em Niterói/RJ

continuidade do movimento das associações e com o Mercosul cada vez mais forte, a disciplina foi se expandindo.

Em 1998, foram publicados os primeiros documentos oficiais que buscaram normatizar a curricularização dessa disciplina em âmbito nacional - os Parâmetros Curriculares Nacionais (PCN), que ressaltaram a função social de seu ensino e o lugar da escola para seu aprendizado, colocando o foco na leitura, em função de objetivos mais imediatos dos estudantes e das possibilidades estruturais das escolas (Brasil, 1998). Neste mesmo ano, chegou ao Brasil o Instituto Cervantes ${ }^{5}$, também com o propósito de formar professores, apesar de isso ferir a nossa legislação (Freitas, 2011). O projeto legalmente fracassou, mas não raras foram as vezes em que o Instituto tentou atuar na formação de professores, reforçando uma prática colonial (e recognitiva), como ocorreu na implementação do espanhol na rede de Niterói, em $2011^{6}$, revelando que essa concepção seguiu nas disputas curriculares. Mais uma vez, vemos o campo do ensino de línguas no Brasil ser atravessado por concepções concorrentes.

Em 2005, foi aprovada a Lei 11.161 que, em função do disposto na LDB, estabelecia a obrigatoriedade da oferta da Língua Espanhola no EM, deixando a matrícula facultativa ao aluno. A partir de sua publicação, o Ministério da Educação (MEC) executou diferentes ações, expandindo-se efetivamente o ensino de Espanhol em redes públicas e privadas. É nesse contexto que, em 2011, a língua entra na rede municipal de Niterói. Para isso, a carga horária das disciplinas foi reajustada e o Espanhol entrou como componente obrigatório, ofertado em dois tempos de aula, para todos os estudantes dos anos finais do EF, que passaram, então, a estudar duas LE - Inglês e Espanhol. Como tempo de aula também é currículo e, portanto, campo de disputas, a ideia foi criticada por alunos e docentes de outras disciplinas, pois tiveram seus tempos de aula reduzidos e, inclusive, seus tempos de intervalo, para que a nova disciplina coubesse no horário regular das escolas.

A cartografia que fizemos até aqui nos mostra diferentes embates discursivos que se dão no processo de constituição da disciplina LE e, especificamente, do Espanhol. Das perspectivas contrastivas às mais utilitárias, passando pela sociolinguística e por ofensivas neocoloniais, tudo isso não se desvincula do próprio processo de inserção da língua nas diferentes redes de ensino. De igual maneira, vemos que tais disputas dificilmente contribuíram para a ruptura de uma política de recognição (Kastrup, 2005; 2012), especialmente, quando observamos o âmbito legal das políticas públicas, uma vez que partem de um mundo dado, impondo perspectivas e processos aos sujeitos que vivenciariam o fazer desta disciplina no espaço escolar.

Sabendo que se trata de apenas um recorte que jamais dará conta de todas as relações possíveis neste campo discursivo (Maingueneau, 2008), optamos por prosseguir a discussão delimitando para análise o espaço discursivo composto pelos enunciados referidos na introdução deste texto. Com base nas relações interdiscursivas materializadas nas 
tramas linguísticas desses enunciados, nas próximas seções, discutiremos as perspectivas praticadas pela política de implementação do ensino de Espanhol na rede municipal Niterói.

\section{Privilégios de Saber na Matriz Curricular de Espanhol}

A rede municipal de Niterói propôs duas versões de seu Referencial Curricular para o ensino de Espanhol. A primeira, publicada em 2011, foi elaborada antes da chegada dos professores dessa língua na rede, e foi instituída pela Portaria FME no 085/2011, tendo sido registrada na publicação Referencial Curricular 2010 - Uma construção coletiva. A segunda - foco das análises - foi desenvolvida em 2012, contando com um grupo de professores de Espanhol efetivos da rede que se voluntariou para a tarefa?

Articulando estudos da Educação e da Linguagem, entendemos que a construção de currículos de LE está atravessada por políticas educacionais, linguísticas e cognitivas e, consequentemente, por diferentes discursos - em concorrência - que as constituem. Do ponto de vista educacional, estamos entendendo currículo como resultado de uma seleção, um espaço de poder, uma questão de identidade e, portanto, como uma invenção social, resultado de um processo histórico ${ }^{8}$ (Silva, 2009).

Assim, currículo envolve disputa de concepções e valores que fundamentam entendimentos acerca do papel do professor e dos estudantes, do material utilizado, dos objetivos da prática educacional e da disciplina, do papel da Educação Básica, entre outros aspectos. O que, por fim, se registrada em documentos curriculares - em âmbito local, regional ou nacional - é o resultado desses confrontos discursivos e não discursivos, isto é, de processos valorativos que privilegiam e marginalizam conhecimentos.

Sob essa ótica, Silva (2009) defende que o currículo não é um objeto pronto, mas sim construído e significado por meio do ponto de vista que se admite como verdadeiro. Entendendo o conhecimento como parte inerente de mecanismos de poder, o autor explica que "[...] o currículo está inextricavelmente, centralmente, vitalmente, envolvido naquilo que somos, naquilo que nos tornamos: na nossa identidade, na nossa subjetividade" (Silva, 2009, p. 15). Esse ponto de vista, ao qual nos alinhamos, reforça a relevância deste estudo, pois associa ao currículo - considerando tudo aquilo que ele valoriza ou invisibiliza - o potencial de produção de subjetividades, de modo que integra um dispositivo político-educacional (Souza, 2019) participante da formação dos sujeitos. Dessa forma, toda estrutura curricular merece espaço para análise e debate sobre o que se elege como legítimo para sua composição, visto que se constitui em modos de ação no que tange à formação de cidadãos.

Adicionalmente, entendemos o currículo pelo viés dos estudos de linguagem, tomando-o como um enunciado realizado por um enuncia- 
Discursos na Institucionalização do Ensino de Espanhol em Niterói/RJ

dor específico (em geral, um enunciador institucional cuja voz em uníssono simula consensos), em um dado lugar e momento. Diante disso, assumimos que os sentidos não são imanentes às palavras, mas produzidos nas diversas situações de enunciação e nas relações sociais e históricas que elas engendram e que, mutuamente, são por elas engendradas, de modo que

Quem se considera filiado à problemática discursiva associa intimamente língua (mais amplamente, os recursos semióticos disponíveis em uma sociedade), atividade comunicacional e conhecimento (os diversos tipos de saberes, individuais e coletivos, mobilizados na construção do sentido dos enunciados) (Maingueneau, 2015, p. 30).

Pautados na compreensão do currículo exposta, prosseguimos com a análise do referencial curricular de Espanhol, partindo do conceito bakhtiniano de gêneros de discurso, visto que promove a compreensão da língua em sua relação com o social. Segundo Bakhtin (2011), todo enunciado se concretiza por meio de gêneros do discurso que são compartilhados socialmente e possuem relativa estabilidade quanto a estrutura composicional, conteúdo temático e estilo.

O filósofo elucida que a estrutura composicional dos gêneros além da temática e do estilo - aponta para a relação de um enunciado com certa atividade humana. Desse modo, entendemos que analisá-la nos dá pistas sobre os sentidos que se constroem acerca do que seria a própria atividade que, em nosso caso, se trata do ensino de LE. Nesse sentido, observando matrizes curriculares pela ótica dos gêneros de discurso, podemos verificar que, com recorrência, enunciados do campo do currículo se manifestam por meio de uma estrutura de tabelas, buscando dar um tratamento objetivo e prático ao objeto de ensino de uma disciplina escolar. Assim, é comum que, por meio desses enunciados, a prática educacional seja significada como algo prescritivel, controlável e objetivo. Encobrem-se, então, todos os conflitos discursivos que caracterizam o processo de construção curricular.

Em uma análise mais detida no aspecto composicional da matriz, é possível notar que, embora siga a estrutura em tabelas - que produz efeitos de sentido de objetividade -, ela se diferencia de matrizes de outras redes pela forma como organiza as informações, estruturando-se em colunas conforme mostra o Quadro 1. 
Quadro 1 - Reprodução da Matriz Curricular de Espanhol do 6 ano/EF

\begin{tabular}{|c|c|c|c|}
\hline $\begin{array}{c}\text { Temáticas } \\
\text { (6ºno })\end{array}$ & $\begin{array}{c}\text { Habilidades / Práti- } \\
\text { cas Cidadãs }\end{array}$ & $\begin{array}{l}\text { Habilidades Espe- } \\
\text { cíficas }\end{array}$ & $\begin{array}{c}\text { Algumas Sugestões } \\
\text { Metodológicas }\end{array}$ \\
\hline $\begin{array}{l}\text { CONTEÚDOS CUR- } \\
\text { RICULARES DE } \\
\text { LÍNGUA ESTRAN- } \\
\text { GEIRA: ESPANHOL } \\
\text { *Tipologia Textual } \\
\text { Predominante: } \\
\text { Descrição } \\
\text { - Alfabeto de A a Z } \\
\text { - Saudações Usuais } \\
\text { (cumprimentos, } \\
\text { agradecimentos, } \\
\text { despedidas) } \\
\text { - Expressões Sociais } \\
\text { - Países e Naciona- } \\
\text { lidades } \\
\text { - Pronomes Pessoais } \\
\text { - Formas de Tra- } \\
\text { tamento (formal e } \\
\text { informal) } \\
\text { - Pontuação Básica } \\
\text { Indefinidos e For- } \\
\text { mas de Contração } \\
\text { - Verbos Irregulares } \\
\text { (ser / estar / tener): } \\
\text { Presente do Indi- } \\
\text { cativo } \\
\text { - Verbo Pronominal } \\
\text { (llamarse): Presente } \\
\text { do Indicativo } \\
\text { - Verbos Regulares: } \\
\text { Presente do Indi- } \\
\text { cativo } \\
\text { - Números Cardi- } \\
\text { nais de 0 a 100 } \\
\text { Artigos Definidos, }\end{array}$ & $\begin{array}{l}\text { - Compreender e } \\
\text { valorizar o papel } \\
\text { da L.E.M. (Língua } \\
\text { Estrangeira Mo- } \\
\text { derna) no processo } \\
\text { de comunicação e } \\
\text { interação humana } \\
\text { - Reconhecer a im- } \\
\text { portância da L.E.M. } \\
\text { (Língua Estrangeira } \\
\text { Moderna) na com- } \\
\text { preensão do mundo } \\
\text { e de outras culturas } \\
\text { - Compreender, } \\
\text { refletir e valorizar a } \\
\text { diversidade cultural } \\
\text { existente no seu } \\
\text { país e entre países } \\
\text { da mesma língua } \\
\text { - Compreender o } \\
\text { papel da língua } \\
\text { como um dos as- } \\
\text { pectos formadores } \\
\text { do ser humano } \\
\text { - Reconhecer que } \\
\text { o aprendizado de } \\
\text { L.E.M. (Língua } \\
\text { Estrangeira Moder- } \\
\text { na) possibilita um } \\
\text { maior entendimen- } \\
\text { to de outros povos e } \\
\text { culturas }\end{array}$ & $\begin{array}{l}\text { - Ler e compreender } \\
\text { textos com peque- } \\
\text { nos diálogos } \\
\text { - Empregar ade- } \\
\text { quadamente as } \\
\text { saudações usuais } \\
\text { - Utilizar expres- } \\
\text { sões em Língua } \\
\text { Espanhola em } \\
\text { situações cotidia- } \\
\text { nas (apresentar-se, } \\
\text { agradecer, pedir } \\
\text { licença, desculpas } \\
\text { etc.) } \\
\text { - Reconhecer e } \\
\text { empregar adequa- } \\
\text { damente palavras } \\
\text { e frases em Língua } \\
\text { Espanhola utili- } \\
\text { zando os nomes de } \\
\text { países, nacionalida- } \\
\text { des, datas comemo- } \\
\text { rativas, hábitos e } \\
\text { costumes culturais } \\
\text { - Inferir o sentido de } \\
\text { frases ou expressões } \\
\text { relacionadas aos pa- } \\
\text { íses pesquisados } \\
\text { - Ler e compreender } \\
\text { pequenos textos } \\
\text { descritivos, identi- } \\
\text { verbais relaciona- } \\
\text { dos aoo tema } \\
\text { ficando suas partes } \\
\text { principais } \\
\text { etconpregar tempos } \\
\text { - Reconhecer e } \\
\text { empregar adequa- } \\
\text { damente palavras } \\
\text { e frases em Língua } \\
\text { Espanhola que } \\
\text { demonstrem a } \\
\text { diversidade cultural } \\
\text { existente em nosso } \\
\text { país (alimentação, } \\
\text { localização das } \\
\text { regiões / estados, } \\
\text { clima, aspectos ge- } \\
\text { ográficos, vestuário }\end{array}$ & $\begin{array}{l}\text { - Identificação de } \\
\text { datas significativas } \\
\text { em seu país e em } \\
\text { países de Língua } \\
\text { Espanhola } \\
\text { - Identificação e } \\
\text { localização em } \\
\text { mapas dos países } \\
\text { que fazem uso da } \\
\text { Língua Espanhola } \\
\text { - Pesquisa (revis- } \\
\text { tas, livros, filmes, } \\
\text { Internet) sobre } \\
\text { os países que têm } \\
\text { como idioma pátrio } \\
\text { a Língua Espanhola, } \\
\text { procurando conhe- } \\
\text { cer /destacar alguns } \\
\text { aspectos da cultura } \\
\text { local } \\
\text { - Trabalho com mú- } \\
\text { sicas selecionadas } \\
\text { em Língua Espa- } \\
\text { nhola, procurando } \\
\text { perceber sons e } \\
\text { diferenças de pro- } \\
\text { núncia } \\
\text { - Pesquisa de letras } \\
\text { de música, com } \\
\text { versão em Língua } \\
\text { Espanhola, que } \\
\text { falem do seu país, } \\
\text { identificando seus } \\
\text { diferentes temas }\end{array}$ \\
\hline
\end{tabular}

Fonte: Referencial Curricular de Língua Espanhola (Prefeitura Municipal de Niterói, 2012). 
Discursos na Institucionalização do Ensino de Espanhol em Niterói/RJ

Identificamos nos títulos das duas primeiras colunas marcas de um diálogo com fundamentos dos PCN, já que a matriz prioriza, entre seus critérios organizacionais e estruturais, os temas e a construção da cidadania, e os PCN promovem como temas centrais

[...] a cidadania, a consciência crítica em relação à linguagem e os aspectos sociopolíticos da aprendizagem de Língua Estrangeira. Esses temas se articulam com os temas transversais dos Parâmetros Curriculares Nacionais, notadamente, na possibilidade de se usar a aprendizagem de línguas como espaço para se compreender, na escola, as várias maneiras de se viver a experiência humana (Brasil, 1998, p. 15).

Uma breve observação da matriz, no entanto, permite constatar que o sentido dado ao termo temática está mais associado a conteúdos linguísticos em um viés estrutural e comunicativista. O que se define como temática é uma seleção de conteúdos linguísticos que podem ser agrupados em categorias as quais denominamos, para efeitos de organização, de linguística textual, vocabulário, gramática. Assim, respectivamente, se elencam conteúdos como: Tipologia Textual Predominante: descrição; Saudações Usuais (cumprimentos, agradecimentos, despedidas); Pronomes Pessoais, Formas de Tratamento (formal e informal), Pontuação Básica.

A segunda coluna trata das habilidades e práticas cidadãs e, como já apontamos, remete a propostas de formação cidadã dos PCNs, as quais se confirmam após uma leitura mais detalhada. Não obstante, segmentar as habilidades cidadãs das ditas temáticas reforça uma tradicional divisão que supervaloriza o conteúdo linguístico. Em outras palavras, mesmo que essas habilidades sejam contempladas, não ganham o status de conhecimento, mantendo-se o privilégio do saber linguístico sistêmico.

Notamos, portanto, como as políticas públicas educacionais disputam espaço na construção de uma matriz curricular com saberes estabelecidos por uma tradição escolar que define o que é aprender/ensinar uma LE. Essa disputa marcou todo o processo de (re)criação dessa segunda versão da matriz de Niterói, uma vez que a própria estrutura do documento, que não poderia ser alterada, não permitia que fossem modificadas as concepções por ela sustentadas. Ao contrastar as duas primeiras colunas, percebe-se que os temas aparecem na coluna de habilidades cidadãs e não na coluna temáticas. Houve, portanto, um esforço para incluir a formação crítica sobre temas envolvidos na vida social dos alunos, mas o modo de organização favorece uma leitura que contrasta conteúdos estruturais e formação crítica.

A coluna habilidades específicas nos dá pista do que se considera a especificidade do ensino do Espanhol. Há um reforço de um sentido de língua como estrutura e instrumento de comunicação ao elencar elementos que majoritariamente se voltam ao estudo do sistema da língua (léxico e gramática), enquadrando-se numa política linguístico-cogni- 
tiva já tradicionalmente posta para o ensino de LE, como vimos na segunda seção deste artigo. Vemos exemplos como: empregar adequadamente as saudações usuais ( $6^{\circ}$ ano), nomear, de forma escrita e oralmente, objetos e pessoas a partir de ilustrações / fotos sobre família (7º ano), reconhecer e empregar adequadamente palavras em Língua Espanhola que indiquem atividades e espaços de lazer ( $8^{\circ}$ ano).

Por fim, observa-se a última coluna das matrizes - algumas sugestões metodológicas -, que se dedica a sugestões de atividades e não, efetivamente, a um passo a passo de como abordar tópicos referidos nas demais colunas. Notamos que parte das atividades sugeridas prioriza os conteúdos linguísticos sistêmicos, havendo também sugestões de produção de textos pelo viés dos gêneros de discurso, mas isso ressalta a falta de coesão do Referencial, pois são gêneros cujo estudo não está previsto pela matriz, tratando-se de reprodução e não de reflexão sobre a língua como social. Dessa forma, o diálogo com o enfoque estrutural segue presente, pois as propostas priorizam pretextos para o uso de vocabulário ou aspectos gramaticais, como em: trabalho com músicas selecionadas em Língua Espanhola, procurando perceber sons e diferenças de pronúncia (6ºno).

Vemos, na proposta curricular, a presença de uma concepção de ensino que valoriza o conhecimento sistêmico superficial, na maioria das vezes, desarticulado de um contexto significativo. Qualitativamente, a maior parte da matriz reforça a visão estruturalista e comunicativista de ensino de línguas, colocando como conteúdos, habilidades específicas e atividades, o reconhecimento e uso da estrutura da língua e de vocabulário, reforçando a lógica da recognição que embasa a trajetória escolar desta disciplina desde seus gestos fundadores. A língua como possibilidade de construção de sentidos, de formas de ver e de inventar o mundo e a nós mesmos fica sem espaço no discurso oficial, comprometendo, por conseguinte, a vinculação da disciplina a um projeto emancipatório de Educação Básica.

\section{O Livro Didático nessa Disputa Curricular}

A seguinte etapa do movimento cartográfico a que nos propomos observa o livro didático adotado pela rede, mapeando as visões de língua presentes em propostas curriculares prescritivas oficiais - compondo nosso espaço discursivo - e permitindo-nos entender o processo de integração da disciplina, como aponta Vargas (2017), dentro de uma cultura escolar.

O primeiro contato que tivemos com a coleção em análise se deu em 2012, quando fomos apresentados, em reunião com a coordenação de Espanhol, ao novo material didático, que havia sido selecionado pela equipe gestora, sem consulta aos professores, e adquirido com verba própria da prefeitura, já que não fazia parte do PNLD. Cabe esclarecer que, à época do PNLD 2011, o Espanhol ainda não integrava o currículo da rede de Niterói. O material era a coleção Ventana al Español (Almei- 
Discursos na Institucionalização do Ensino de Espanhol em Niterói/RJ

da; Amendola, 2011), produzida após o PNLD 2011, mas não inserida no de 2014. Não se pode afirmar, porém, que tenha sido reprovada nesse processo, pois a lista de coleções reprovadas não é divulgada pelo MEC.

Entendendo que o currículo é também aquilo que dele se faz (Silva, 2009), sabemos que se materializa não só em matrizes curriculares, mas também na escolha de livros didáticos que buscam direcionar e prescrever práticas docentes e discentes em sala de aula, como referência do que se deve ensinar e aprender em uma dada disciplina. Desse modo, trata-se de um conjunto de enunciados sobre conhecimentos privilegiados e formas de conceber a língua [estrangeira].

Nesta seção, com base em Vargas (2017), nosso foco recai sobre a análise de fragmentos de apresentação da coleção didática direcionados ao docente - em seu Manual do Professor (MP) - e da forma como a coleção se organiza, entendendo que isso também evoca concepções de [ensino de] língua, de aprendizagem etc.

O seguinte fragmento aparece na introdução do MP, dedicada a apresentar as concepções teórico-metodológicas da coleção e sugestões para o trabalho em sala de aula:

La colección se ha elaborado con el objetivo de servir de base para un proceso valioso de aprendizaje de español [...] y se apoya en una concepción de lengua extranjera (LE) como instrumento de comunicación y conocimiento que permite al alumno insertarse en otra comunidad discursiva, a fin de ampliar su visión de mundo y exponer ideas con claridad y seguridad. [...] La colección ofrece a los alumnos una diversidad de textos auténticos de diferentes géneros y tipos, así como una variedad de propuestas de trabajo con esos textos, a fin de insertarles en situaciones de uso de la lengua que sean lo más reales posibles (Almeida; Amendola, 2011, p. 2).

A partir desse trecho, é possível observar que, mesmo aderindo a uma concepção de língua como instrumento de comunicação, indo, portanto, contra a proposta dos PCN, o livro, ao se apresentar aos docentes, coloca o aluno (e não a língua) em uma posição central, uma vez que é ela, a língua, que lhe serve para a ampliação de sua visão de mundo e para a exposição de ideias. Além disso, destaca o trabalho realizado com os textos - revelando uma discrepância com a perspectiva colocada nos referenciais curriculares da rede, já que tais referenciais, como vimos, priorizavam o trabalho com os elementos sistêmicos da língua (lexicais e gramaticais).

Ainda na introdução, na subseção Visión de lenguaje y de lengua, o livro explica que sua perspectiva de língua é a "[...] de una actividad social e interactiva situada (quienes usan la lengua consideran el público al cual se dirigen o quién ha producido el enunciado), así que se relacionan aspectos históricos y discursivos y se observa la lengua en su funcionamiento social, cognitivo e histórico" (Almeida; Amendola, 2011, p. 2). Citando Bakhtin, afirma ainda que, nessa concepção, "[...] el ser humano usa el lenguaje para actuar en el contexto social, pues 
lengua y lenguaje son concebidos como formas de acción social como espacios de interlocución que permiten la práctica de los más diversos tipos de actos" (Almeida; Amendola, 2011, p. 2-3). Vemos, assim, que o livro se apresenta ao docente a partir de uma perspectiva inventiva, propondo o aprendizado para a construção de possibilidades de atuar no mundo, o que evidencia como posicionamentos discursivos concorrem para a construção de sentidos de ensino-aprendizagem de LE, uma vez que apresentam-se ao professor concepções diferentes das postas na matriz curricular da rede.

Em seguida, ao apresentar sua concepção de avaliação e a organização do material, os autores citam os PCN como base teórica, reforçando sua vinculação a um percurso regulador oficial (Vargas, 2017), mesmo em uma obra que não apareceu como aprovada nos dois editais do PNLD. Por outro lado, se afasta da proposta curricular da rede, uma vez que a perspectiva de língua adotada na organização dos conteúdos, como vimos, é outra. Nesse sentido, a obra adere a concepções e discursos que se apresentam em um documento que abrangeria o país inteiro, uma vez que o público que deseja atingir não se restringe a uma única rede. Entretanto, foi selecionada para ser usada em uma rede cujas orientações curriculares não se alinham às postas no documento nacional.

Ao observarmos como o livro apresenta suas seções aos professores, notamos que essas disputas curriculares se materializam de novas maneiras. Em relação ao trabalho com a leitura - o foco dos PCN -, por exemplo, o livro o distribui em três seções: ¿Qué sabes?; ¡A empezar! e Contextos. A seção ¿Qué sabes? teria como objetivo “[...] determinar el conocimiento del alumno sobre el tema planteado" (Almeida; Amendola, 2011, p. 4), através de um trabalho com perguntas de pré-leitura. A seção A empezar, segundo o MP, teria por finalidade desenvolver a compreensão auditiva e leitora dos alunos, uma vez que, primeiramente o aluno escuta a gravação - na qual se lê ou se interpreta o texto - e depois lê o texto escrito. Esses textos são apresentados, pela obra, como sendo de complexidade gradual e representando gêneros diversos. O objetivo da seção seria levar o aluno a desenvolver e empregar “[...] estrategias de lectura que lo llevarán a procesos de inferencia a partir del texto leído, construyendo la lectura a través de su conocimiento textual y de mundo" (Almeida; Amendola, 2011, p. 4).

Mesmo ao vincular-se aos PCN, a obra aponta para a possibilidade de que os textos (e não o trabalho com eles) possam ser organizados em uma complexidade gradual, o que contraria as bases teóricas dos parâmetros. Assim, a obra propõe - como os PCN, mas em oposição aos referenciais da rede - que a leitura ocupe uma posição central, ao mesmo tempo em que sustenta uma linearidade no trabalho com a linguagem, contrariando os PCN e alinhando-se, nesse sentido, à linearidade proposta pelos referenciais da rede. Isso mostra como as disputas entre posicionamentos discursivos e políticas cognitivas estão imbricadas ao ensino de LE, evidenciando a construção curricular como campo de embates.

Educação \& Realidade, Porto Alegre, v. 46, n. 2, e108008, 2021. 
Discursos na Institucionalização do Ensino de Espanhol em Niterói/RJ

Em relação à seção Contextos, o livro explica que o objetivo é ampliar o trabalho com os textos na coleção e que, nela, "Se expone al alumno al reconocimiento de diferentes géneros textuales, con actividades que unen comprensión lectora y análisis de los componentes intrínsecos del tipo textual" (Almeida; Amendola, 2011, p. 5). O trabalho com gêneros e tipologias textuais cria aproximação a uma visão social da língua, conforme os PCN, entretanto, dentro da obra, os gêneros trabalhados não dialogam necessariamente com as temáticas e demais seções das unidades, podendo ser entendidos como um trabalho extra, o que se evidencia ao observarmos que o trabalho com o texto não entra nas unidades de revisão.

Analisando a organização do livro, inicialmente, notamos que os títulos das unidades fazem referência aos temas nelas trabalhados e apresentam uma relação direta com os conteúdos lexicais focalizados (por exemplo, no livro do $6^{\circ}$ ano, El mundo habla español, Hola, ¿qué tal?, Hora de aprender, Lazos de família, Cómo somos, Mi casa, tu casa). Vemos, assim, que o foco, tal como nos referenciais da rede, está no conhecimento sistêmico, parcialmente articulado, no livro, a um contexto (Vargas, 2017). Destacamos que as temáticas apresentadas não coincidem plenamente com as temáticas propostas pelo Referencial e tampouco dialogam com o entendimento de temas transversais propostos nos PCN, visto que estão mais comprometidas com o pretexto do estudo de vocabulário ou estruturas linguísticas do que com a promoção do entendimento da língua como social e seu papel na formação cidadã.

Vale explicar que as unidades se organizam com um padrão, inclusive em relação ao tamanho e número de páginas que ocupam suas seções, o que revela uma busca de controle pelo processo de ensinoaprendizagem incompatível com as bases teóricas citadas no próprio livro. São elas, respectivamente:

Quadro 2 - Ventana al Español - seções

\begin{tabular}{|c|l|}
\hline Seção & \multicolumn{1}{|c|}{ Foco } \\
\hline Abertura & $\begin{array}{l}\text { (a) página dupla com uma imagem e três subseções: } \\
\text { Serás capaz de... (objetivos da unidade); ¿ué sabes? } \\
\text { (questões de conhecimento prévio sobre o tema } \\
\text { tratado); e A empezar (escuta de uma gravação - di- } \\
\text { álogos artificiais produzidos para o livro ou textos da } \\
\text { internet e/ou de outras fontes, adaptados ou não - e } \\
\text { questões sobre essa gravação); } \\
\text { (b) versão escrita do texto ouvido acompanhada de } \\
\text { questões de leitura }\end{array}$ \\
\hline Vocabulário (em geral: listas de palavras e/ou exer- \\
cícios de repetição).
\end{tabular}

Fonte: Elaboração dos autores. 
Essa distribuição das seções revela, além da busca pelo controle do processo, como concorrem diferentes perspectivas de língua dentro de um mesmo livro. Entretanto, todas elas apontam para uma mesma política de recognição, na qual o aprendiz tem pouca oportunidade para se pensar como sujeito que aprende uma língua e que a utiliza para construir-se a si mesmo e ao mundo, algo revelado pela ênfase que se dá ao vocabulário e aos elementos gramaticais tratados no limite da frase, e que, por sua vez, acaba estando em diálogo com o apresentado nos referenciais da rede.

O texto, portanto, possui lugares bastante delimitados, apresentando-se como elemento central na abertura e no encerramento das unidades. Entretanto, ainda que sejam selecionados ou criados em função do vocabulário neles apresentados, nota-se um trabalho com a leitura e com a escuta que, em alguns casos, extrapola o pretexto para o aprendizado de palavras e de estruturas gramaticais (Vargas, 2017). Bem como na proposta curricular da rede, a gramática e o vocabulário são trabalhados aqui como elementos descontextualizados, sem que estejam inseridos efetivamente em textos analisados pelos alunos. Os textos da última seção, que buscam embasar um trabalho a partir de gêneros específicos podem ser entendidos como elementos extras, não articulados à proposta ampla da unidade. Vemos esse mesmo fenômeno na citação de algumas tipologias textuais apresentadas de maneira descontextualizada na proposta curricular da rede.

Por fim, notamos, que a visão de ensino de LE predominante é a mesma, posto que se continua acreditando na aprendizagem pela repetição e na interação ainda como reprodução de fórmulas sistematizadas. Mesmo que os PCN sejam citados como documento norteador, o documento aparece apenas como simulacro (Maingueneau, 2008). Na disputa de saberes que é a construção de um enunciado curricular, o livro mantém uma perspectiva presa à tradição de práticas das décadas anteriores, bem como ocorre nos referenciais da rede. A obra avança minimamente ao abrir mais espaço para a abordagem do texto, do mesmo modo como nos referenciais concorrem vozes que defendem uma visão de língua associada à formação cidadã, dialogando, ainda que de maneira muito restrita, com a Linguística Textual, no entanto, as análises corroboram que, em ambos os casos, prepondera uma visão tradicional acerca das línguas e do ensino de LE no contexto escolar.

\section{O Papel do SAEN na Política Curricular de Língua Espanhola}

Nesta seção, buscamos trazer os debates, compreendidos discursivamente, que se colocam sobre o tema do Currículo e sua relação com as discussões que se fazem sobre a avaliação. Avaliação e currículo, portanto, apresentam-se como campos profundamente integrados, de modo que se retroalimentam, concorrendo ambos para a materialização, em sala de aula, de políticas educacionais, linguísticas e cognitivas:

O que se avalia e como se avalia está condicionado pelas competências, habilidades, conhecimentos que o cur- 
Discursos na Institucionalização do Ensino de Espanhol em Niterói/RJ

rículo privilegia ou secundariza. Os valores e as lógicas de avaliação reproduzem os valores, lógicas e hierarquias que selecionam, organizam os conhecimentos nos currículos. Por sua vez, o que se privilegia nas avaliações escolares e nacionais determina as competências e conhecimentos privilegiados ou secundarizados no currículo. Reorientar processos e critérios de avaliação implica em reorientar a organização curricular e vice-versa (Fernandes; Freitas, 2007, p. 13).

Dentro dessa concepção, entendemos que a avaliação é (ou deveria ser) parte de uma ação coletiva de formação dos estudantes, sendo, portanto, responsabilidade tanto da coletividade como de cada indivíduo que dela faz parte. Nesse sentido, seu processo de desenvolvimento envolveria diferentes esferas e objetivos (Fernandes; Freitas, 2007).

Em nosso caso, as análises se voltam a uma avaliação no nível macro que busca avaliar o sistema educacional da rede municipal de Niterói, por meio de provas padronizadas realizadas por seus estudantes. Assim, não podemos ignorar que também pretenderia avaliar as práticas desenvolvidas em sala de aula, uma vez que os alunos fazem individualmente suas provas e elas revelam seus níveis de conhecimento sobre o que foi selecionado pelas provas e avaliam as escolas, na medida em que os resultados dos alunos de cada escola são sistematizados e organizados de forma que seja possível medir o desempenho de seus alunos, tomados como um conjunto, na realização da prova.

Nesse sentido, não podemos ignorar os impactos que a avaliação em nível macro constrói sobre os currículos escolares (Sousa, 2003), bem como o fenômeno descrito por Esteban (2008) de retorno, atualmente, a um padrão de avaliação definido pela avaliação quantitativa, tomada como "[...] mecanismo de controle dos tempos, dos conteúdos, dos processos, dos sujeitos e dos resultados escolares" que contribuiria para a construção da qualidade da educação, considerada em função do "[...] conhecimento que foi transmitido para os alunos e retido por eles" (Esteban, 2008, p. 10).

Assim, segundo a autora, consolida-se um modelo híbrido, no qual "[...] o contexto escolar adquire um certo grau de liberdade, mas os processos pedagógicos continuam vinculados a um produto previamente determinado" (Esteban, 2008, p. 11). Tal produto, em nosso caso, é previamente determinado, de um lado, por uma matriz curricular e, por outro, por um livro didático, além de ser avaliado por uma prova institucional, aplicada a todos os estudantes da rede. Assim, pretendese avaliar, ao mesmo tempo, a aprendizagem dos alunos, a atuação dos professores e a qualidade da rede como um todo, postas no modelo previamente definido, voltado para a reprodução, ou seja, para a efetivação de políticas de recognição (Kastrup, 2005; 2012).

Especificamente, o SAEN foi instituído no ano de 2013 pela Lei Municipal no 3.067. Dentro desse sistema, incluiu-se o programa Avaliar para Conhecer, no qual os alunos realizam provas para, segundo a Prefeitura, avaliar seu nível de conhecimento. Nesta seção, o foco está 
nas provas de Espanhol do primeiro exame - realizado em 2013 -, seguindo com o mapeamento das políticas curriculares da rede para esta disciplina.

Oficialmente, a proposta do Sistema é que, a partir da avaliação, fossem implementadas iniciativas com o objetivo de aprimorar a qualidade do ensino. Aqui, é interessante ressaltar que, como apontam Vasconcellos e Maurício (2018, p. 200), apesar de o SAEN oficialmente buscar avaliar não apenas a aprendizagem dos estudantes em relação a um currículo pretendido, “[...] os aspectos de participação, protagonismo e a intenção de avaliar outras vertentes que influenciam o processo educacional [...] não se configuram no Contexto da Prática, ou seja, no cotidiano escolar, os professores não percebem os desdobramentos e a abrangência do SAEN".

A prova de Língua Espanhola foi aplicada apenas para os alunos dos $8^{\circ}$ e $9^{\circ}$ anos do EF e, sobre esse critério de escolha metodológica de aplicação do exame, não foram encontrados documentos que o justificassem, já que a disciplina era ofertada para alunos de todas as séries dessa etapa de ensino. A prova continha dez questões de múltipla escolha, com quatro opções de respostas, baseadas em textos ou fragmentos de texto, como se pode ver a seguir:

\section{Quadro 3 - Reprodução da questão 14}

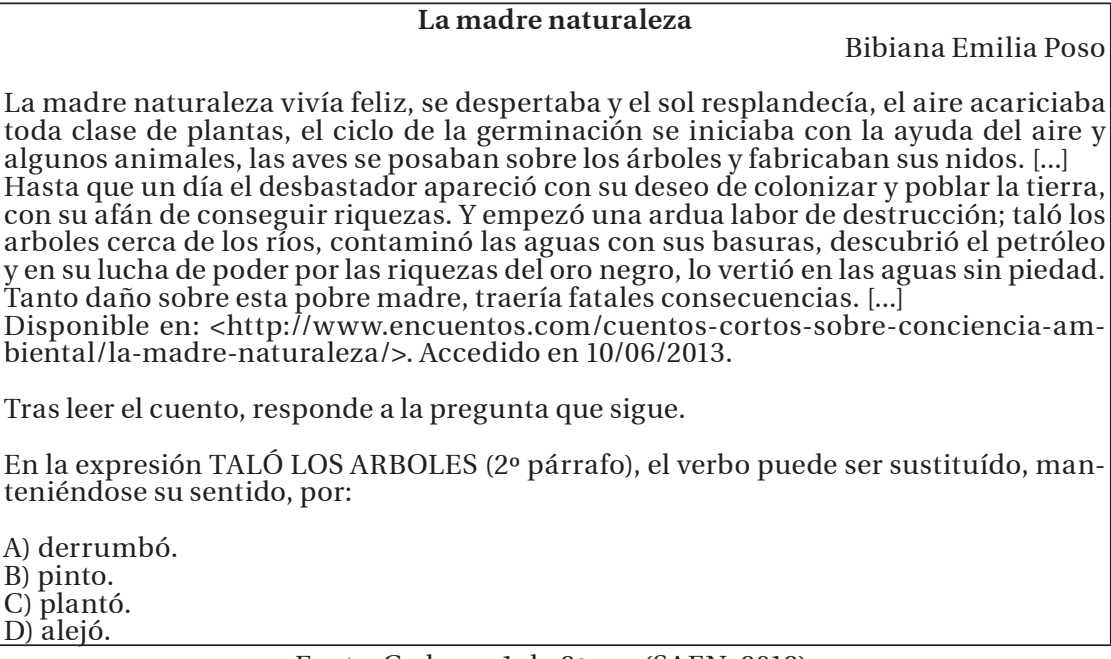

Fonte: Caderno 1 do $8^{\circ}$ ano (SAEN, 2013). 
Conhecer buscava mais preparar os estudantes para essas grandes avaliações do que verificar em que medida os conteúdos previstos na proposta curricular da rede estavam sendo trabalhados.

Em relação ao teor das questões propostas, encontramos o seguinte panorama:

Quadro 5 - Natureza das Questões de Espanhol SAEN 2013

\begin{tabular}{|l|c|c|}
\hline \multicolumn{1}{|c|}{ Natureza da questão } & $\mathbf{8}^{\mathbf{0}}$ ano & $\mathbf{9}^{\mathbf{0}}$ ano \\
\hline Conhecimento gramatical & 4 & 2 \\
\hline Conhecimento lexical & 2 & 2 \\
\hline Localização de informações explícitas & 1 & 2 \\
\hline Localização de informações implícitas & 1 & 2 \\
\hline Análise de conectores & 2 & 1 \\
\hline Identificação de referentes & $\mathbf{1 0}$ & $\mathbf{1 0}$ \\
\hline \multicolumn{2}{|c|}{ Total } & 0 \\
\hline
\end{tabular}

Fonte: Elaboração dos autores.

O Quadro 5 reforça a discrepância entre a proposta de avaliação e as orientações curriculares, uma vez que os conteúdos (ou as habilidades) exigidos nas questões não constavam nas diretrizes da rede. No entanto, em relação às políticas cognitivas, nota-se um diálogo, pois a visão predominante é a de um mundo dado, em que falante e língua encontram-se apartados. Na prova, ainda é visível uma concepção estrutural de língua, já que o texto aparece sempre como pretexto para sua reprodução (identificação de referentes ou de informações explícitas ou implícitas, por exemplo) ou para a identificação de elementos linguísticos sistêmicos (conhecimentos lexicais, gramaticais ou análise de conectores, por exemplo). Não há espaço, nessa prova de leitura, para que o estudante efetivamente se mostre como leitor, coparticipante da formação dos sentidos a partir da interlocução viabilizada pelo ato de ler.

Ainda assim, o texto não é pretexto necessariamente para a avaliação de conteúdos previstos no currículo oficial ou mesmo no currículo pretendido pelo livro didático usado na rede. Nota-se a ausência de questões que abordem os modos de organização de textos; nenhuma valorização da questão dos temas que participam da formação cidadã e um tratamento superficial da leitura, reforçando um descompromisso do discurso oficial no que concerne ao engajamento do ensino de língua espanhola a um projeto de formação básica crítica e emancipatória. Além disso, os temas colocados nos textos presentes na avaliação, em sua maioria, não dialogam com os temas postos no referencial curricular e, quando o fazem, a temática não é trabalhada nas questões. Igualmente, as questões não priorizam o que se coloca nas habilidades cidadãs, nem o que se coloca como seleção de conteúdos linguísticos.

Apresentam-se, dessa maneira, dentro das políticas oficiais educacionais da rede, diferentes concepções de linguagem e de ensino de 
Discursos na Institucionalização do Ensino de Espanhol em Niterói/RJ

língua em disputa e, consequentemente, diferentes políticas linguísticas, ainda que se situem dentro de uma mesma política cognitiva de reprodução de saberes dados. Nesse sentido, o diálogo entre avaliação e currículo é entrecortado por essas formas diferentes de entender a língua e seu ensino. Vista sob essa perspectiva, a proposta da rede parece um aglomerado sem muita reflexão. Entretanto, é importante lembrar que ela manifesta (e põe em disputa) saberes derivados de uma tradição escolar e de outras políticas educacionais, como o PNLD e as avaliações em larga escala.

\section{Considerações Finais}

A proposta deste texto foi construir um mapeamento de políticas envolvidas na implementação do Espanhol na rede de Niterói. Tais políticas são atravessadas por posicionamentos discursivos que envolvem concepções de Educação Básica e de ensino de LE vinculadas a diferentes projetos de formação. Nesse sentido, de modo a dar visibilidade aos conflitos, nosso primeiro movimento cartográfico se deu na compreensão do campo discursivo sobre o qual nos debruçamos - o das políticas educacionais/curriculares de ensino de LE - e, em seguida, na definição do espaço discursivo, chegando aos três enunciados-documento analisados.

Nesse sentido, entendemos que formulação, implementação e consolidação de políticas educacionais/curriculares, processualmente, envolvem disputas que constroem a história de uma disciplina na escola brasileira. Assim, olhar especificamente para o Espanhol nos ajuda a entender como as políticas públicas colocaram-no, em tão pouco tempo, de um lugar de extrema oficialidade (inserida em leis de diferentes níveis governamentais) a uma posição de fragilidade, eliminando-o completamente das políticas educacionais nacionais.

O mapeamento construído mostra que a Língua Espanhola não conseguiu construir um lugar efetivo para si, ao menos não na rede de Niterói, mesmo sendo obrigatória para o terceiro e quarto ciclos do EF. Não negamos o fato de que todo saber colocado em sala de aula é reflexo de uma disputa político-discursiva e que, portanto, é sempre provisório. Entretanto, se compararmos a Língua Espanhola com outras disciplinas da rede, dentro das mesmas ações aqui analisadas, poderemos ver maior estabilidade no alinhamento das propostas curriculares e de avaliação.

A trajetória percorrida nos colocou diante de um cenário em que se privilegiam concepções de ensino de LE vinculadas a um entendimento de língua como estrutura e como instrumento de comunicação, desvinculando-a de seu potencial de produção de subjetividades, de realidades, de relações sociais, de seu papel na construção de relações de alteridade e na leitura do mundo. Retomando o histórico que cartografamos no início deste artigo, se o ensino de Espanhol se fortalece e se oficializa também vinculado ao Mercosul, ou seja, a uma política essencialmente econômica, não é de se estranhar que uma visão mais 
utilitária da língua se fortalecesse, bem como acontece com o ensino de Inglês, língua conhecida como dos negócios.

Considerando, ainda, que tais políticas são decorrentes de estabilizações discursivas provisórias, no contexto atual, diante de uma ofensiva neoliberal e neocolonial que vincula a educação à formação de mão de obra acrítica descomprometida com a luta pela construção de uma sociedade menos excludente, vemos como a supervalorização do Inglês, marcada na (des)reforma do Ensino Médio e na BNCC, reforça tais discursos não só por ser uma medida centralizadora, mas por seu caráter homogeneizante, antidemocrático e associado a um projeto de formação para o mercado de trabalho.

Todo esse cenário revela o lugar de fragilidade que o Espanhol e todas as LE ocupam no currículo escolar e, portanto, é fundamental construirmos esse debate se desejamos alterar esse lugar. Entendemos que esse debate não deve estar guiado apenas pela defesa de uma disciplina ou de posições teóricas sobre ela, mas dentro de uma reflexão ampla sobre "[...] por que frequentar a escola, sobre o que é mais importante aprender e sobre aquilo que queremos conhecer" (Fernandes; Freitas, 2007, p.36).

O caminho a percorrer é longo, mas esperamos, com este artigo, contribuir para reflexões que articulem Educação e Estudos de Linguagem, de modo a incrementar nossa visão crítica das implicações da construção, implementação e consolidação de políticas educacionais e dos diferentes discursos que não cessam de concorrer para dar sentidos a projetos de Educação Básica. E, quem sabe, com algum otimismo, possamos incentivar políticas não mais de recognição, mas de invenção (Kastrup, 2005), em que nossos estudantes sejam protagonistas de seus processos de aprendizado de LE, disputando sentidos de mundo e de suas existências nele.

Recebido em 30 de setembro de 2020 Aprovado em 4 de janeiro de 2021

\section{Notas}

1 Sobre isso, recomendamos a leitura de Souza (2019) e Giorgi et al. (2018).

2 Cabe ressaltar que, apesar de nós como pesquisadores adotarmos o conceito de línguas adicionais, tal como posto por Schlatter e Garcez (2012), para definir as línguas que optamos por adicionar ao nosso repertório linguístico, aqui utilizamos o termo línguas estrangeiras porque é essa a nomenclatura que aparece nos documentos curriculares oficiais.

3 Entendemos como educação linguística as práticas vivenciadas pelos sujeitos, em diferentes espaços sociais, envolvidas na construção de conhecimentos linguísticos, envolvendo usos, crenças, normas, preconceitos etc.

4 Trata-se de um princípio da pesquisa cartográfica, que direciona a relação do pesquisador com o que pesquisa e com os sujeitos da pesquisa, no sentido de que traçar um plano comum de participação no fazer investigativo. Profundamente vinculada ao viés interventivo, se relaciona também ao compromisso do 
Discursos na Institucionalização do Ensino de Espanhol em Niterói/RJ

pesquisador de contribuir para a criação de um mundo em que as diferenças existam em um espaço comum (Barros; Kastrup, 2012).

5 Órgão do Ministério de Educação da Espanha que busca fomentar o ensino do Espanhol universalmente.

6 Para saber mais sobre manifestações contrárias à intervenção do Instituto na formação de professores da rede, acessar:<https://espanholdobrasil.wordpress. com>.

7 Os autores deste artigo integraram tal grupo.

8 Este artigo discute o aspecto prescritivo dos enunciados curriculares, porém entendemos que o currículo se materializa em aula, quando os sujeitos sociais, suas experiências e seus saberes disputam espaço no processo de construção do conhecimento com os saberes oficializados (Arroyo, 2011).

\section{Referências}

ALMEIDA, Adriana Pedro; AMENDOLA, Roberta (Org.). Ventana al Español 1. Livro do Professor. São Paulo: Moderna/Santillana, 2011.

ARROYO, Miguel. Currículo, Território de Disputas. Petrópolis: Ed. Vozes, 2011. BAKHTIN, Mikhail. Gêneros de Discurso. In: BAKHTIN, Mikhail. Estética da Criação Verbal. São Paulo: WMF Martins Fontes, 2011. P. 261-306.

BARROS, Laura Pozzana; KASTRUP, Virgínia. Cartografar é Acompanhar Processos. In: PASSOS, Eduardo; KASTRUP, Virgínia; ESCÓSSIA, Liliana (Org.). Pistas do Método da Cartografia: pesquisa-intervenção e produção de subjetividade. Porto Alegre: Sulina, 2012. P. 52-75.

BRASIL. Secretaria de Educação. Parâmetros Curriculares Nacionais: terceiro e quarto ciclos do ensino fundamental - língua estrangeira. Brasília: Secretaria de Educação Fundamental, 1998.

CELADA, Maria Teresa; GONZÁLEZ, Neide Therezinha Maia. Los Estudios de Lengua Española en Brasil. ABEH, São Paulo, Consejería de Educación, n. 10, p. 35-58, 2000.

DAHER, del Carmen. Enseñanzas del Español y Políticas Lingüísticas en Brasil. Hispanista, Niterói, n. 27, p. 1-12, 2006.

ESTEBAN, Maria Teresa. A Avaliação no Cotidiano Escolar. In: ESTEBAN, Maria Teresa (Org.). Avaliação: uma prática em busca de novos sentidos. Petrópolis: DPetAlli, 2008. P. 07-24.

FERNANDES, Claudia; FREITAS, Luiz Carlos. Indagações sobre Currículo: currículo e avaliação. Brasília: MEC/SEB, 2007.

FREITAS, Luciana Maria Almeida de. Entre Lembranças e Esquecimentos: relato memorialístico sobre o ensino de espanhol no Rio de Janeiro. Hispanista, Niterói, v. 12, n. 46, p. 1-25, 2011.

FREITAS, Luciana Maria Almeida de; BARRETO, Talita. Construindo uma História: a APEERJ e o ensino de Espanhol no Brasil. ABEH, São Paulo, Consejería de Educación, n. 17, p. 65-69, 2007.

GERHARDT, Ana Flávia Lopes Magela. As Identidades Situadas, os Documentos Curriculares e os Caminhos Abertos Para o Ensino de Língua Portuguesa no Brasil. In: GERHARDT, Ana Flávia Lopes Magela; AMORIM, Marcel Alvaro; CARVALHO, Álvaro Monteiro (Org.). Linguística Aplicada e Ensino: língua e literatura. Campinas: Pontes, 2013. P.77-113. 
GIORGI, Maria Cristina; DAHER, Del Carmen; VARGENS, Dayala Paiva de Medeiros; MELO, Fabiany Carneiro. Em Tempos de Neocolonialismo: escolar sem partido ou escolar partida? Arquivos Analíticos de Política Educativas, v. 26, n. 90, p. 1-18, 2018.

KASTRUP, Virginia. Políticas Cognitivas na Formação do Professor e o Problema do Devir-Mestre. Educação \& Sociedade, Campinas, v. 26, n. 93, p. 12731288, set./dez. 2005.

KASTRUP, Virginia. Conversando sobre Políticas Cognitivas e Formação Inventiva. In: DIAS, Rosimeri. Oliveira (Org.). Formação Inventiva de Professores. Rio de Janeiro: Lamparina, 2012. P. 52-60.

LEFFA, Vilson José. Metodologia do Ensino de Línguas. In: BOHN, Hilário; VANDRESEN, Paulino. Tópicos em Lingüística Aplicada: o ensino de línguas estrangeiras. Florianópolis: Ed. UFSC, 1988. P. 211-236.

MAINGUENEAU, Dominique. Gênese dos Discursos. São Paulo: Parábola, 2008. MAINGUENEAU, Dominique. Discurso e Análise do Discurso. São Paulo: Parábola, 2015.

PREFEITURA MUNICIPAL DE NITERÓI. Referencial Curricular de Língua Espanhola. [Documento digital]. Niterói: Fundação Municipal de Educação, 2012. RAJAGOPALAN, Kanavillil. Por uma Lingüística Crítica: linguagem, identidade e questão ética. São Paulo: Parábola, 2003.

RODRIGUES, Fernanda dos Santos Castelano. Leis e línguas: o lugar do espanhol na escola brasileira. In: BARROS, Cristiano; COSTA, Elzimar. Espanhol: ensino médio - coleção explorando o ensino. Brasília: MEC/SEB, 2010. P. 13-24.

SCHLATTER, Margarete; GARCEZ, Pedro. Línguas adicionais na escola: aprendizagens colaborativas em Inglês. Erechim: Edelbra, 2012.

SILVA, Tomaz Tadeu da. Documentos de Identidade: uma introdução às teorias do currículo. Belo Horizonte: Autêntica, 2009.

SOUSA, Sandra Maria Zákia Lian. Possíveis Impactos das Políticas de Avaliação no Currículo Escolar. Cadernos de Pesquisa, Fundação Carlos Chagas, São Paulo, n. 119, p. 175-190, jul. 2003.

SOUZA, Alice Moraes Rego de. Base Nacional Comum para quê/quem?: uma cartografia de conflitos discursivos na produção de um currículo oficial. 2019. 362 f. Tese (Doutorado em Estudos da Linguagem) - Programa de Pós-graduação em Estudos da Linguagem, Universidade Federal Fluminense, Niterói, 2019. VARGAS, Diego da Silva Vargas. O plano inferencial de leitura e o ensino de espanhol na escola brasileira: cognição distribuída, políticas cognitivas e livro didático. 2017. Tese (Doutorado em Letras Neolatinas) - Programa de Pósgraduação em Letras Neolatinas, Universidade Federal do Rio de Janeiro, 2017.

VASCONCELLOS, Carla Cristina Martins da Conceição; MAURÍCIO, Lúcia Velloso. Sistema de Avaliação da Educação de Niterói: a percepção de professores no contexto da prática. Revista Teias, UERJ, Rio de Janeiro, v. 19, n. 54, p. 193-208, jul./set. 2018.

Diego da Silva Vargas é Doutor em Letras Neolatinas, Mestre em Letras Vernáculas, Bacharel e Licenciado em Letras - Português/Espanhol pela UFRJ e Especialista em Psicopedagogia (IAVM-UCAM). É Professor Adjunto do Departamento de Didática da Universidade Federal do Estado do Rio de Janeiro (UNIRIO). Pesquisa nos campos de Educação e de Letras, com ênfase 
Discursos na Institucionalização do Ensino de Espanhol em Niterói/RJ

em Linguística Aplicada e Educação Linguística.

ORCID: https://orcid.org/0000-0001-6292-256X

E-mail: dsvargas04@yahoo.com.br

Alice Moraes Rego de Souza é Doutora em Estudos de Linguagem pela UFF, Mestre em Linguística e Licenciada em Letras Português/Espanhol pela UERJ. Professora de língua espanhola e portuguesa no Cefet/RJ Petrópolis. Pesquisa nas áreas de análise do discurso, currículo e formação de professor, linguística aplicada e ensino de língua estrangeira.

ORCID: https://orcid.org/0000-0003-3618-7199

E-mail: alice.souza@cefet-rj.br

Editora-responsável: Beatriz Vargas Dorneles

Este é um artigo de acesso aberto distribuído sob os termos de uma Licença Creative Commons Atribuição 4.0 Internacional. Disponível em: <http:// creativecommons.org/licenses/by/4.0>. 